\title{
Genetic Diversity and Structure in a Collection of Ancient Spanish Pear Cultivars Assessed by Microsatellite Markers
}

\author{
Carlos Miranda ${ }^{1}$, Jorge Urrestarazu, Luis G. Santesteban, and José B. Royo \\ Departamento de Producción Agraria, Universidad Pública de Navarra, Campus de Arrosadia 31006 \\ Pamplona, Spain \\ Valero Urbina \\ Departament d'Hortofructicultura, Botànica i Jardinería, Universitat de Lleida, Avda Alcalde Rovira \\ Roure, 191, 25198 Lleida, Spain
}

\begin{abstract}
AdDitional INDEX wORDS. Pyrus communis, SSR, identification, germplasm, core collection
Abstract. A collection of 141 old and local Spanish accessions of pear (Pyrus communis) from the Escuela Técnica Superior de Ingeniería Agraria-Universidad de Lleida (ETSIA-UdL) Pear Germplasm Bank in Lleida, Spain, were studied using a set of eight microsatellite markers to estimate the genetic diversity of the collection, to identify the genetic structure and relationships among its accessions, and to establish a representative core collection. An additional set of 13 well-known pear cultivars, currently grown in Spain and which represent a wide genetic diversity, were added as reference. The eight simple sequence repeat (SSR) loci amplified 97 alleles, with nine to 15 alleles per locus, and with the expected heterozygosity ranging from 0.65 to 0.89 . All of the accessions except for 16 had at least one of the 48 rare alleles (frequency $<0.05$ ) identified, and seven unique alleles were found in six accessions. Fifteen accessions were identified as synonyms and were excluded from the analysis. Genetic analyses performed by hierarchical clustering, Bayesian modelbased clustering, and factorial correspondence analysis supported the existence of three groups among the accessions with moderate [fixation index $\left(\mathrm{F}_{\mathrm{ST}}\right)=\mathbf{0 . 0 7 4}$ ], but significant, differentiation. As a whole, most of the germplasm (about $\mathbf{7 5 \%}$ ) curated at the collection showed its genetic distinctness with respect to the main pear cultivars used in European orchards. In fact, most reference cultivars were included in one single cluster that, moreover, had the lowest genetic diversity and allelic richness, in spite of having been chosen as heterogeneous material from different origins. The obtained results were also used to create a core collection with 35 accessions constituting an efficient and accessible entry point in the ETSIA-UdL pear collection for breeding and research communities.
\end{abstract}

Pear (Pyrus spp.) is one of the most important fruit crops of the Rosaceae family, ranking second to apple (Malus $\times$ domestica) in world and European production of pome fruit tree species (Food and Agriculture Organization of the United Nations, 2010). Pyrus communis is the most commonly cultivated pear species in Europe, America, and Africa, whereas Pyrus pyrifolia is the main cultivated species in Asia (Bell, 1991). Worldwide production of $P$. communis pears is based upon relatively few cultivars, most of them selected in late 18th and 19th century, or derived from those. Furthermore, the genetic base of cultivated pear in western Europe has significantly narrowed in the last few years. In 1986, seven cultivars accounted for $\approx 58 \%$ of pear production in western Europe (Bell, 1991), but nowadays, seven cultivars account for $75 \%$ of the production (World Apple and Pear Association, 2009). 'Conference' has become predominant in most European producing countries, and accounts for nearly one-third of European Union production. The reasons for this concentration are varied, but include economic and market factors, changes in consumption patterns, and biological aspects, such as productivity, storage ability, and susceptibility to pests and diseases (Bell, 1991).

Received for publication 10 May 2010. Accepted for publication 28 June 2010. Financial support for this work was provided by INIA, Instituto Nacional de Investigación y Tecnología Agraria y Alimentaria (project grant nos. RF2004008-C03-00, RFP2004-009, and RFP-0000-68).

${ }^{1}$ Corresponding author. E-mail: carlos.miranda@unavarra.es.
As a consequence, many of the traditional or local cultivars have been considered obsolete and replaced, leading to a dramatic loss of genetic diversity. The recognition of the need for the collection and preservation of endangered fruit germplasm has encouraged the establishment of genetic resource conservation programs. In 1986, a germplasm bank of old and local pear cultivars was established by the Horticulture section of the ETSIA-UdL. This germplasm bank currently maintains 114 Malus and 169 Pyrus accessions, collected at 12 northern Spanish provinces (Urbina et al., 2007), at the Estación Experimental de Lleida of the Institut of Recerca i Tecnologia Agroalimentària (IRTA) in Lleida, Spain. In 2002, a research program was launched to evaluate the genetic diversity of the collection through detailed morphological and agronomical description, and fingerprinting analysis based upon molecular markers was initiated in 2005.

Microsatellite or simple sequence repeat (SSR) markers have been favored over other methods in establishing unique genetic identities or fingerprints and in assessing genetic diversity within a collection due to their high polymorphism level, reproducibility, and relative ease of analysis (Schlötterer, 2004). Moreover, SSR have also proven useful in creating core collections that represent not only the genetic structure of germplasm collections, but also their phenotypic structure (Santesteban et al., 2009). The SSR markers used in the earliest studies in pear were derived from apple (Yamamoto et al., 2001; Hemmat et al., 2003), as apple proved to be highly conserved in pear. However, after the development of SSR derived from asian pear (P. pyrifolia) and 
Table 1. Pear accessions maintained by the Escuela Técnica Superior de Ingeniería Agraria - Universidad de Lleida (ETSIA-UdL) Germplasm Bank and reference cultivars that were included in the study, in alphabetical order. Accessions selected to constitute the core collection are indicated in bold. Collection information includes accession name and bank code, site of collection, specific latitude and longitude, approximate elevation, and collecting source code according to Food and Agriculture Organization of the United Nations/International Plant Genetic Resources Institute (FAO/IPGRI, 2001) multicrop passport descriptors.

\begin{tabular}{|c|c|c|c|c|c|c|}
\hline Accession name $^{z}$ & Accession code & Site of collection in Spain & Latitude & Longitude & Elevation $(\mathrm{m})$ & Collecting source $^{\mathrm{y}}$ \\
\hline Agramunt - 1 & PRF-135 & Puigvert d'Agramunt, Lleida & 41.78 & 1.13 & 360 & 23 \\
\hline Agua & PRF-030 & Nalda, La Rioja & 42.33 & -2.48 & 530 & 23 \\
\hline Agua Iglesia & PRF-028 & Lardero, La Rioja & 42.42 & -2.45 & 435 & 23 \\
\hline Agua Magistral & PRF-029 & Lardero, La Rioja & 42.40 & -2.47 & 460 & 23 \\
\hline Aguilar - 1 & PRF-011 & Aguilar de Campoo, Palencia & 42.78 & -4.25 & 900 & 23 \\
\hline Almenar - 1 & PRF-071 & Almenar, Lleida & 41.77 & 0.62 & 270 & 62 \\
\hline Angelina & PRF-141 & Isona i Conca Dellà, Lleida & 42.08 & 1.12 & 1000 & 23 \\
\hline Areny - 1 & PRF-091 & Areny de Noguera, Huesca & 42.25 & 0.73 & 670 & 62 \\
\hline Areny - 2 & PRF-092 & Areny de Noguera, Huesca & 42.25 & 0.73 & 675 & 62 \\
\hline Areny - 3 & PRF-093 & Areny de Noguera, Huesca & 42.25 & 0.73 & 675 & 62 \\
\hline Areny - 4 & PRF-113 & Areny de Noguera, Huesca & 42.25 & 0.72 & 750 & 23 \\
\hline Azucar verde - 1 & PRF-007 & Albelda de Iregua, La Rioja & 42.37 & -2.47 & 490 & 21 \\
\hline Azucar verde - 2 & PRF-008 & Albelda de Iregua, La Rioja & 42.37 & -2.47 & 490 & 21 \\
\hline Balaguer - 1 & PRF-066 & Balaguer, Lleida & 41.75 & 0.77 & 220 & 23 \\
\hline Balaguer - 2 & PRF-067 & Balaguer, Lleida & 41.75 & 0.77 & 220 & 23 \\
\hline Balaguer Flix - 1 & PRF-046 & Balaguer, Lleida & 41.73 & 0.93 & 290 & 62 \\
\hline Balaguer Flix - 2 & PRF-047 & Balaguer, Lleida & 41.73 & 0.93 & 290 & 23 \\
\hline Balaguer Flix - 3 & PRF-048 & Balaguer, Lleida & 41.73 & 0.93 & 290 & 23 \\
\hline Balaguer Flix - 4 & PRF-049 & Balaguer, Lleida & 41.73 & 0.93 & 290 & 23 \\
\hline Balaguer Flix - 5 & PRF-050 & Balaguer, Lleida & 41.73 & 0.93 & 290 & 23 \\
\hline Balaguer Flix - 6 & PRF-051 & Balaguer, Lleida & 41.73 & 0.93 & 290 & 23 \\
\hline Balart & PRF-070 & Almenar, Lleida & 41.77 & 0.58 & 280 & 23 \\
\hline Benavent de la Conca - 1 & PRF-142 & Benavent de la Conca, Lleida & 42.08 & 1.12 & 985 & 23 \\
\hline Bergamota & PRF-112 & Sopeira, Huesca & 42.33 & 0.73 & 780 & 23 \\
\hline Bescanó - 1 & PRF-121 & Bescanó, Girona & 41.97 & 2.75 & 110 & 23 \\
\hline Bescanó - 2 & PRF-122 & Bescanó, Girona & 41.97 & 2.72 & 110 & 23 \\
\hline Biscarri - 1 & PRF-143 & Biscarri, Lleida & 42.12 & 1.12 & 920 & 23 \\
\hline Blanca d'aigua & PRF-079 & Baix Pallars, Lleida & 42.33 & 1.00 & 1075 & 25 \\
\hline Blanquilla durró & PRF-102 & La Vall de Boí, Lleida & 42.48 & 0.82 & 1480 & 23 \\
\hline Blanquilla rosada & PRF-058 & Huesa del común, Teruel & 41.05 & -0.93 & 820 & 21 \\
\hline Bodegas Lardero & PRF-017 & Lardero, La Rioja & 42.42 & -2.47 & 435 & 23 \\
\hline Bossost - 1 & PRF-107 & Bossòst, Lleida & 42.78 & 0.68 & 720 & 23 \\
\hline Bossost - 2 & PRF-108 & Bossòst, Lleida & 42.78 & 0.68 & 720 & 23 \\
\hline Campanilla Lardero & PRF-018 & Lardero, La Rioja & 42.42 & -2.47 & 435 & 23 \\
\hline Castelldans -1 & PRF-130 & Castelldans, Lleida & 41.52 & 0.77 & 240 & 62 \\
\hline Clota & PRF-042 & Miralcamp, Lleida & 41.60 & 0.90 & 260 & 62 \\
\hline Coll - 1 & PRF-036 & Barruera, Lleida & 42.47 & 0.78 & 1180 & 23 \\
\hline Coll - 2 & PRF-037 & Barruera, Lleida & 42.47 & 0.78 & 1180 & 23 \\
\hline Coll - 3 & PRF-038 & Barruera, Lleida & 42.47 & 0.78 & 1180 & 23 \\
\hline Colorada de juliol & PRF-081 & Lleida, Lleida & 41.62 & 0.60 & 185 & 23 \\
\hline Cor podrit & PRF-072 & Almenar, Lleida & 41.77 & 0.62 & 270 & 62 \\
\hline Coure & PRF-116 & Olot, Girona & 42.15 & 2.55 & 560 & 40 \\
\hline Cristóbal de Bejar - 1 & PRF-039 & Cristóbal, Salamanca & 40.45 & -5.87 & 870 & 23 \\
\hline De Agua de agosto & PRF-061 & Valls de Aguilar, Lleida & 42.22 & 1.35 & 530 & 62 \\
\hline De Batre & PRF-059 & Els Alamus, Lleida & 41.62 & 0.65 & 230 & 62 \\
\hline De Campana & PRF-083 & Castell de Mur, Lleida & 42.10 & 0.90 & 370 & 23 \\
\hline De Cuixa & PRF-062 & Valls de Aguilar, Lleida & 42.22 & 1.35 & 540 & 62 \\
\hline De invierno & PRF-111 & Vielha e Mijaran, Lleida & 42.70 & 0.78 & 1040 & 23 \\
\hline Donguindo & PRF-012 & Fuenmayor, La Rioja & 42.45 & -2.55 & 435 & 23 \\
\hline Donguindo & PRF-009 & Lardero, La Rioja & 42.42 & -2.45 & 435 & 21 \\
\hline Durro - 1 & PRF-101 & Durró, Lleida & 42.48 & 0.82 & 1460 & 23 \\
\hline Durro - 2 & PRF-103 & Durró, Lleida & 42.48 & 0.82 & 1470 & 23 \\
\hline Durro - 3 & PRF-104 & Durró, Lleida & 42.48 & 0.82 & 1470 & 23 \\
\hline Durro - 4 & PRF-105 & Durró, Lleida & 42.48 & 0.82 & 1425 & 23 \\
\hline
\end{tabular}


Table 1. Continued.

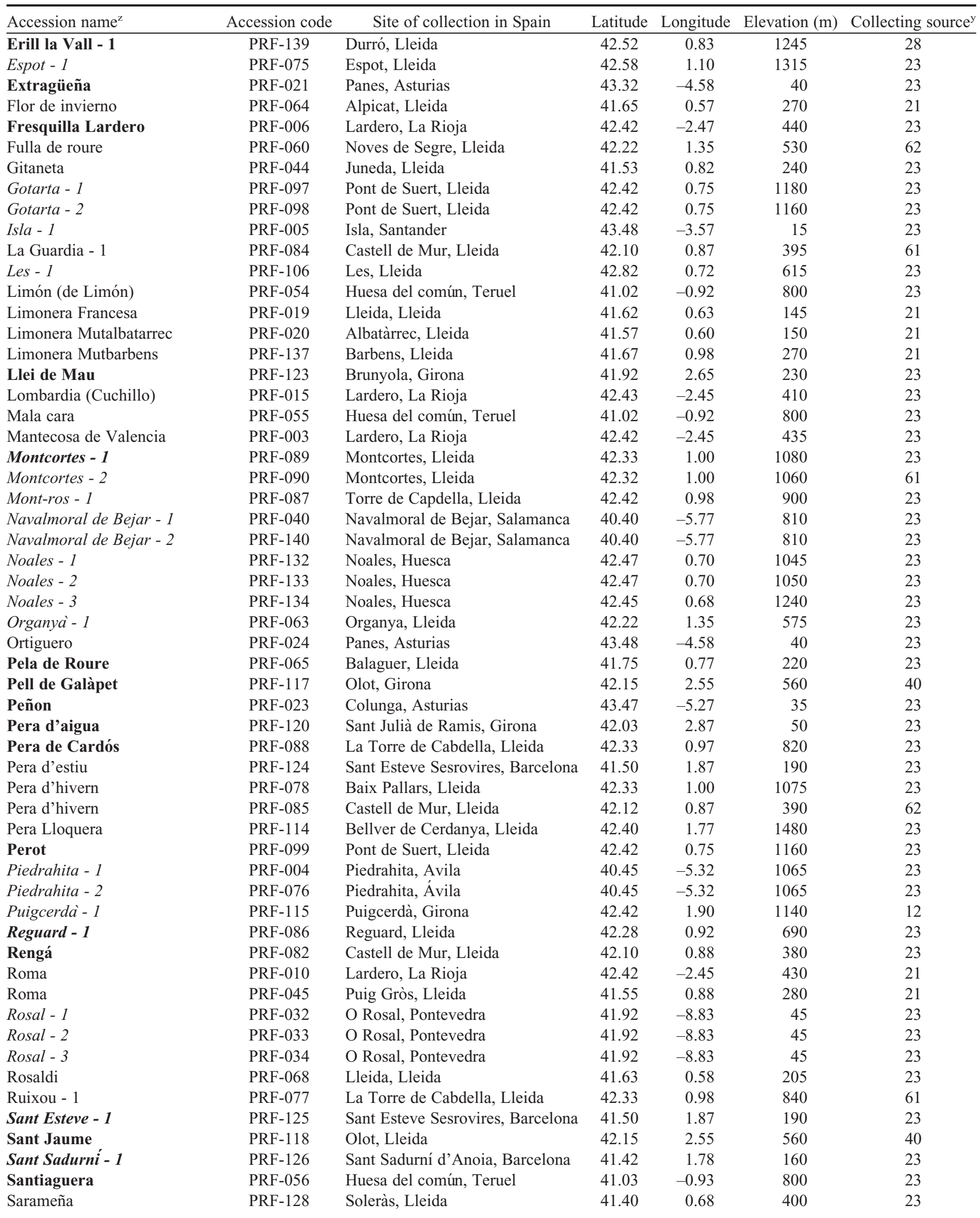


Table 1. Continued.

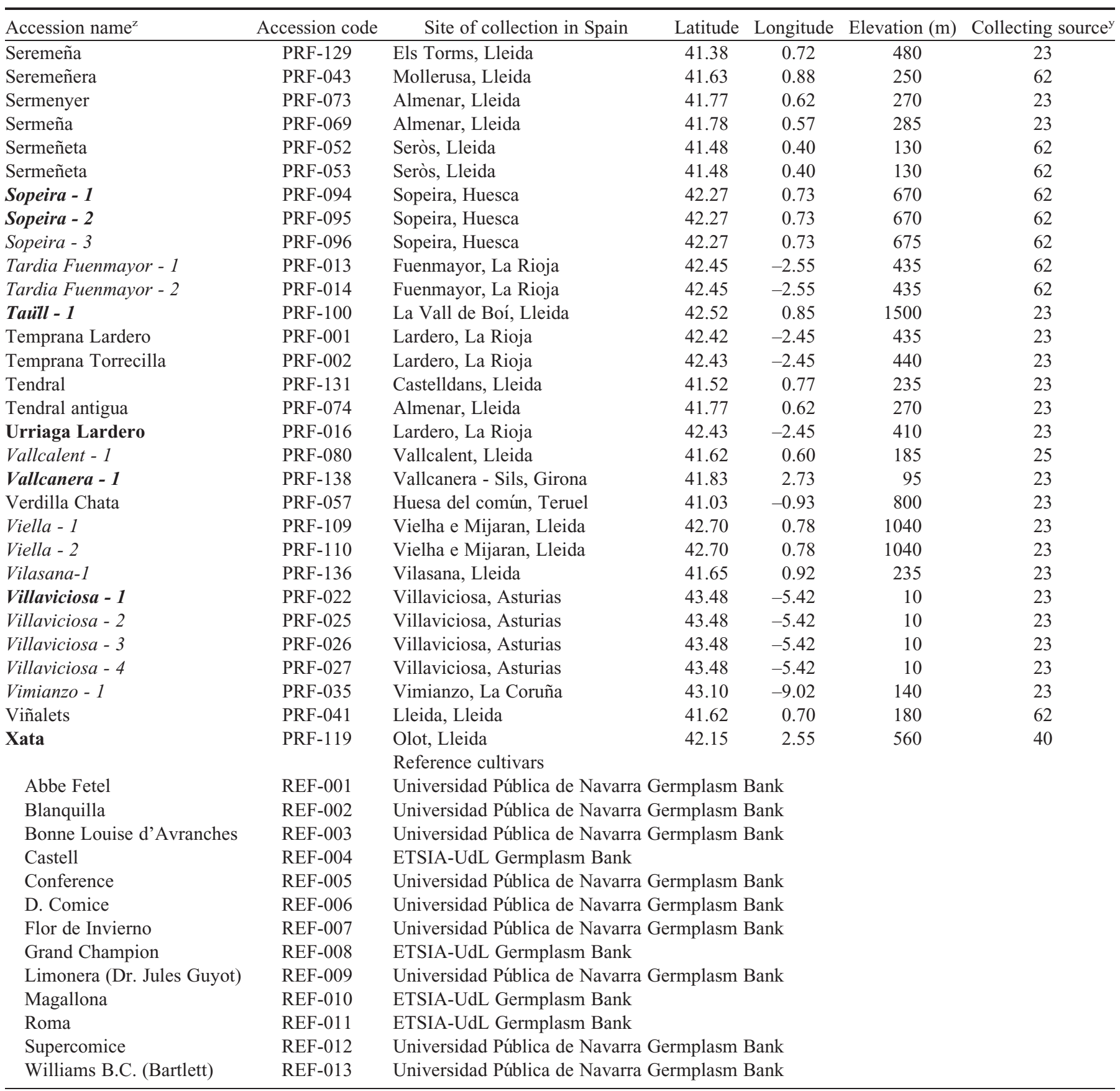

${ }^{\mathrm{z}}$ Accessions in italics were named after the village in which they were collected.

${ }^{y}$ FAO/IPGRI (2001) codes for collecting source: $12=$ shrubland, $21=$ field, $23=$ backyard or home garden, $25=$ pasture, $28=$ park, $40=$ institute, 61 = roadside, 62 = road margin.

european pear ( $P$. communis) (Fernández-Fernández et al., 2006; Yamamoto et al., 2002a, 2002b), SSR derived from Malus and Pyrus have been used to reveal pear genetic diversity among pear cultivars (Bao et al., 2007; Bassil et al., 2008, 2009; Brini et al., 2008; Ghosh et al., 2006; Jiang et al., 2009; Katayama et al., 2007; Kimura et al., 2002; Sisko et al., 2009; Volk et al., 2006; Wünsch and Hormaza, 2007; Xuan, 2008).

The present study aims to determine the genetic identity of the Pyrus accessions curated at the ETSIA-UdL Germplasm Bank, to estimate the genetic diversity of the collection, to identify the genetic structure and relationships among its accessions, and to establish a representative core collection, using a set of highly informative SSR markers, to optimize the conservation and use of this germplasm.

\section{Materials and Methods}

Plant material. One hundred forty-one pear accessions, collected from 12 different provinces in northern Spain, were used for this study. The plant material is maintained in the pear collection of the ETSIA-UdL Germplasm Bank. The collection is composed of old and local pear cultivars, and the name and 
origin of each accession is given in Table 1. All the accessions were prospected from singular trees that at the moment of their collection were actively cultivated (in backyards or small farms) or were abandoned old trees. When the accession was prospected in an abandoned spot and its local denomination could not be known, it was named after the village where it was obtained (indicated by italics in Table 1). All of the accessions have been characterized phenotypically in an earlier work (Urbina et al., 2007).

An additional set of 13 well-known pear cultivars was obtained from the pear collections of ETSIA-UdL and Universidad Pública de Navarra (UPNA, Pamplona, Spain) and has been included in the analysis as a reference. Reference cultivars were chosen among those currently grown in Spain and aiming, at the same time, to represent a wide variability and genetic diversity (Wünsch and Hormaza, 2007). The commercial importance of these cultivars is, nevertheless, very different: six cultivars (Abbe Fetel, Blanquilla, Conference, Comice, Limonera, and 'Williams') account for $>80 \%$ of pear production in Spain and $\approx 70 \%$ in western Europe (World Apple and Pear Association, 2009); four cultivars (Flor de Invierno, Castell, Roma, and Magallona) are old cultivars that remain important in Spain at a regional level, and the remaining three cultivars (Bonne Louise, Grand Champion, and Supercomice) are used mainly as pollenizers or are cultivated to some extent in a few regions.

SSR ANALYSIS. Total genomic DNA from all pear cultivars included in Table 1 was extracted from young leaves according to the Fulton et al. (1995) protocol. Extracted DNA was quantified in a spectrophotometer (Biomate-3; Thermo Spectronic, Rochester, NY). Ten SSR primer pairs developed from european and asian pear (Yamamoto et al., 2002c), and four developed from apple (Gianfranceschi et al., 1998) were used for the initial assay, and eight were chosen after gel clarity and reliability of alleles (Table 2). Polymerase chain reactions (PCR) were performed in a final volume of $15 \mu \mathrm{L}$ containing $75 \mathrm{ng}$ of genomic DNA, $0.2 \mu \mathrm{M}$ primer, $0.2 \mathrm{~mm}$ of each dNTPs, $1.5 \mathrm{~mm} \mathrm{MgCl}_{2}, 1 \times$ reaction buffer, and 1.0 units of Taq polymerase (Biotools, Madrid, Spain). Reactions were carried out in a thermal cycler (model 2720; Applied Biosystems, Foster City, CA) with the following temperature profile: an initial 2.5 -min denaturation step at $94^{\circ} \mathrm{C}$, followed by 30 cycles

Table 2. Microsatellite code, linkage group, size range, number of alleles per locus (A), number of effective alleles per locus $\left(\mathrm{A}_{\mathrm{e}}\right)$, observed $\left(\mathrm{H}_{\mathrm{o}}\right)$ and expected $\left(\mathrm{H}_{\mathrm{e}}\right)$ heterozygosity, Nei diversity index $(\mathrm{DI})$, and discriminant power $\left(\mathrm{P}_{\mathrm{D}}\right)$ of eight SSR loci analyzed in 126 unique european pear accessions of the Escuela Técnica Superior de Ingeniería Agraria - Universidad de Lleida (ETSIA-UdL) pear collection.

\begin{tabular}{lcrcccccc}
\hline Locus $^{z}$ & $\begin{array}{c}\text { Linkage } \\
\text { group no. }\end{array}$ & $\begin{array}{c}\text { Size range } \\
(\mathrm{bp})\end{array}$ & $\mathrm{A}$ & \multicolumn{1}{c}{$\mathrm{A}_{\mathrm{e}}$} & $\mathrm{H}_{\mathrm{o}}$ & $\mathrm{H}_{\mathrm{e}}$ & $\mathrm{DI}$ & $\mathrm{P}_{\mathrm{D}}$ \\
\hline CH01h10 & 8 & $102-126$ & 10 & 6.04 & 0.70 & 0.83 & 0.84 & 0.94 \\
NB103a & 5 & $82-138$ & 15 & 6.37 & 0.76 & 0.84 & 0.85 & 0.95 \\
NB105a & 11 & $144-186$ & 11 & 6.91 & 0.89 & 0.86 & 0.86 & 0.96 \\
NB106a & 9 & $84-134$ & 14 & 6.42 & 0.75 & 0.84 & 0.85 & 0.94 \\
NB109a & 3 & $128-206$ & 15 & 9.34 & 0.91 & 0.89 & 0.90 & 0.97 \\
NH023a & 3 & $120-174$ & 12 & 2.89 & 0.51 & 0.65 & 0.66 & 0.81 \\
NH029a & 9 & $86-106$ & 9 & 5.96 & 0.87 & 0.83 & 0.84 & 0.94 \\
RLG1-1 & 1 & $196-238$ & 11 & 6.97 & 0.58 & 0.86 & 0.86 & 0.94 \\
Total & & & 97 & 51.41 & & & & \\
Avg & & & 12.13 & 6.36 & 0.74 & 0.83 & 0.83 & 0.93 \\
\hline
\end{tabular}

zPrimer pairs developed by Yamamoto et al. (2002c), except for CH01h10, which was developed by Gianfranceschi et al. (1998). of $30 \mathrm{~s}$ at $94{ }^{\circ} \mathrm{C}, 1 \mathrm{~min}$ at annealing temperature and $1 \mathrm{~min}$ at $72{ }^{\circ} \mathrm{C}$, and a final 5 -min extension step at $72{ }^{\circ} \mathrm{C}$. The annealing temperature used was $50{ }^{\circ} \mathrm{C}$ for all loci except for NB103a $\left(42{ }^{\circ} \mathrm{C}\right)$ and NB106a and RLG-1 $\left(47^{\circ} \mathrm{C}\right)$. PCR products were separated and detected on an acrylamide gel using a Sequi-Gen GT (Bio-Rad, Hercules, CA) sequencing unit, and they were visualized by silver staining (Bassam et al., 1991). A 30- to 330bp AFLP DNA ladder (Invitrogen Life Technologies, Barcelona, Spain) was used as the molecular size standard. The bands of amplified DNA were scored manually.

Diversity ANALYSIS. All unambiguous fragments corresponding to SSR markers were scored for the presence (1) and absence (0) of each band. The genetic information was assessed using the following parameters: number of alleles per locus (A), effective number of alleles $\left[A_{e}=\left(\sum p_{i}\right)^{-1}\right.$, where $p_{i}$ is the frequency of the $i^{\text {th }}$ allele], number of rare alleles per locus ( $\mathrm{B}=$ no of alleles with frequency $<0.05)$, observed heterozygosity $\left(\mathrm{H}_{\mathrm{o}}\right.$, direct count $)$, expected heterozygosity $\left(\mathrm{H}_{\mathrm{e}}=\right.$ $1-\sum \mathrm{p}_{\mathrm{i}}{ }^{2}$ ), and Nei's diversity index (DI) (Nei, 1987). Discrimination power [PD (Tessier et al., 1999)] was also calculated according to the latter formula, where $\mathrm{p}_{\mathrm{i}}$ represents the frequency of the $i^{\text {th }}$ genotype.

Analysis OF Genetic STRUCTURe. To assess the structure of the genetic diversity within the collection, we used three approaches: graphic clustering from similarity data, Bayesian ( similarity between accessions was calculated with absence data for each accession according to Nei and $\mathrm{Li}$ (1979) and the unweighted pair group method with arithmetic mean (UPGMA) clustering with Phylip 3.65 (Felsenstein, 1989). analysis was performed with 5000 replicates. We also mented in STRUCTURE 2.2 (Pritchard et al., 2000). We used the admixture model and 250,000 iterations were computed lowing a 75,000 iteration burn-in period. Each Markov chain from one to 10 . We used the $\Delta k$ method described by Evanno et al. (2005) to examine the rate of change in successive posterior robabilities over a range of $k$ values and to estimate the appropriate $k$ value. A genotype was assigned to the group for which it had the highest membership coefficient. Modal assignment across all replicate runs was used to determine the final placement of a genotype in a group, and the results were visualized in a barplot using Distruct (Rosenberg, 2004). Finally, multivariate analyses were performed with GENETIX 4.05 software (Belkhir et al., 2004 ) by FCA. Rare alleles (frequency below $2 \%$ ) were eliminated and considered as missing data because they may bias analyses (Breton et al., 2008).

The genetic structure of the collection was further investigated by a hierarchical analysis of molecular variance (AMOVA) using ARLEQUIN 3.11 (Excoffier et al., 2005). The significance of the partitioning of genetic variance among groups was tested. Groups were defined according to clusters obtained by the Bayesian analysis. Descriptive statistics, including variation between clusters $\left(\mathrm{F}_{\mathrm{ST}}\right)$ and diversity within groups including Nei's DI, number of polymorphic alleles, and 
allelic richness (El Mousadik and Petit, 1996), were estimated using ARLEQUIN and FSTAT (Goudet, 1995).

Construction of THE CORE COLlection. The number and selection of accessions for inclusion in the core set was identified using the MSTRAT software (Gouesnard et al., 2001), based upon the maximization (M-strategy) of the number of alleles retained in each locus (Schoen and Brown, 1995). We used Nei's DI (Nei, 1987) as a second maximization approach. Optimal core size was identified using the feature of MSTRAT that measures and plots the fraction of total diversity retained in cores of increasing size. We performed 20 independent sampling runs and identified the inflection point on the resulting mean curvilinear plot as the optimal core size (Gouesnard et al., 2001). Once the appropriate core size was identified, we examined 20 possible core sets and developed a consensus set retaining the most commonly found accessions among the 20 replicate core sets. The representativeness of the core collection was validated according to the following criteria (modified from Brown, 1989, Grenier et al., 2000): 1) recovery of all the alleles present in the whole collection, 2) no significant differences in the frequency distribution of frequent alleles in at least $95 \%$ of loci between the core and the whole collection (evaluated with chi-square), and 3) no significant differences in variability parameters $\left(\mathrm{H}_{\mathrm{o}}\right.$ and $\left.\mathrm{H}_{\mathrm{e}}\right)$ between the core subset and the entire collection (evaluated by Friedman's repeated measures analysis). All the comparisons were carried out with SPSS (version 15.0; SPSS, Chicago).

\section{Results and Discussion}

SSR POLYMORPHISM. The eight SSR loci amplified a total of 97 alleles in the 154 pear cultivars analyzed (141 local accessions and 13 reference cultivars), varying from nine (NH029a) to 15 (NB109a) alleles per locus, with an average of 12.13 alleles per locus, and the effective number of alleles being 6.43 (Table 2). $\mathrm{H}_{\mathrm{o}}$ ranged from 0.51 (NH023a) to 0.91 (NB109a), with an average of 0.74 , whereas $\mathrm{H}_{\mathrm{e}}$ ranged from 0.65 (NH023a) to 0.89 (NB109a), with an average of 0.83 . Nei's DI was high $(>0.8)$ for all SSR loci except for NH023a $(\mathrm{DI}=0.66)$. The mean estimate of power of discrimination $\left(\mathrm{P}_{\mathrm{D}}\right)$ was relatively high, with an average value of 0.93 , and ranged from 0.64 for NH023a to 0.97 for NB109a. All accessions, except 16, had at least one of the 48 rare alleles identified. Accessions that contributed most in terms of rare alleles were 'Sant Sadurni-1' and 'Rengá', with seven rare alleles each. A total of seven unique alleles (alleles present in only one accession) was found in six accessions (Table 3 ).

Reliable genetic markers are essential for efficient cultivar identification and the establishment of genetic relationships among them. The eight SSR markers used in this study have proven their reliability in assessing identities and diversity retained within the ETSIA-UdL pear germplasm collection. The overall allelic diversity displayed by the eight SSR loci has revealed a high genetic variation in the pear germplasm included in this study. The results for allelic number per locus fall within the range of values reported for SSR studies of cultivated P. communis genotypes (Bassil et al., 2008, 2009; Brini et al., 2008; Sisko et al., 2009; Wünsch and Hormaza, 2007, Xuan, 2008). $H_{e}$ summarizes the fundamental genetic variation of a population or species in a single parameter (Berg and Hamrick, 1997) and, for that reason, is a commonly used genetic DI that allows comparisons with the literature. The average $\mathrm{H}_{\mathrm{e}}$ found in our study $\left(\mathrm{H}_{\mathrm{e}}=0.83\right)$ is slightly higher than values reported by other studies of variation in $P$. communis germplasm performed with different sets of SSRs and fewer cultivars (Bassil et al., 2008, 2009; Brini et al., 2008; Sisko et al., 2009; Wünsch and Hormaza, 2007, Xuan, 2008).

Cultivar IDentification. Seven groups of synonyms, including 22 accessions as a whole, were identified (Table 4). Some were expected because the accessions received very similar or identical denominations, such as the identity groups of 'Limonera', 'Roma', and 'Blanquilla' types. However, other groups of synonymies are composed of accessions that have different names (or were unknown) and geographical origin, probably indicating the spread of selected plants through grafting. On the other hand, several homonyms have also been shown: both 'Pera d'Hivern' accessions (PRF-078 and PRF085 ) differed at the eight loci and shared only four alleles. The same situation was observed for both 'Tendral' accessions (PRF-131 and PRF-074), and one of the 'Limoneras' (PRF137) that shared only six alleles with the rest of them. The accession called 'Blanquilla Durro' differs from the rest of 'Blanquillas', but it is probably a descendant of unknown pedigree, as it shares one allele with 'Blanquilla' on each of the eight loci analyzed. Finally, slight differences (just one allele at NB105a loci) were detected between the two accessions named

Table 3. Unique simple sequence repeat alleles in the Escuela Técnica Superior de Ingeniería Agraria - Universidad de Lleida (ETSIAUdL) pear collection.

\begin{tabular}{lcl}
\hline Locus & Allele $(\mathrm{bp})$ & \multicolumn{1}{c}{ Accession name (code) } \\
\hline NB103a & 138 & Sant Jaume (PRF-118) \\
NB105a & 150 & Pera d'Aigua (PRF-120) \\
NB106a & 114 & Donguindo Venta Lardero (PRF-009) \\
NH023a & 136 & Taúll-1 (PRF-100) \\
& 140 & Peñon (PRF-023) \\
& 148 & Donguindo Venta Lardero (PRF-009) \\
NH029a & 106 & Sopeira-2 (PRF-095)
\end{tabular}

${ }^{\mathrm{z}}$ Numbers in parentheses correspond to the accession codes listed in Table 1.

Table 4. Synonyms identified in the Escuela Técnica Superior de Ingeniería Agraria - Universidad de Lleida (ETSIA-UdL) pear collection by SSR fingerprinting.

Identity

group Synonyms [name (code) $]^{\mathrm{z}}$

1 Flor de invierno (REF-007), Flor de Invierno (PRF-064), Piedrahita-2 (PRF-076)

2 Villaviciosa-2 (PRF-025), Villaviciosa-4 (PRF-027)

3 Limonera (REF-009), Limonera francesa (PRF-019), Limonera Mutalbatarrec (PRF-020)

4 Roma (REF-011), Roma Acedas (PRF-010), Roma Arbeca-1 (PRF-045)

5 Pela de Roure (PRF-065), Balaguer Flix-5 (PRF-050), La Guardia-1 (PRF-084), Pera d'Hivern (PRF-085), De Invierno (PRF-111), Coure (PRF-116)

6 Blanquilla (REF-002), Blanquilla Rosada (PRF-058)

7 Donguindo Venta Lardero (PRF-009), Donguindo

Fuenmayor (PRF-012), Cristobal de Bejar-1 (PRF-039)

${ }^{\mathrm{z}}$ Numbers in parentheses correspond to the accession codes listed in Table 1 . 
'Azúcar Verde'. This minor difference can be due to some somatic mutation that it is known to occur in long-lived trees that have been vegetatively propagated by grafting. All in all, 15 genotypes that were identified as 'synonyms' were not considered further in the analysis of genetic diversity, which was therefore restricted to the remaining 126 .

Genetic Relationships AMONG CULTIVARS. Pairwise Nei and Li genetic similarity coefficients ranged from 0.057 to 0.938 . Except for 'Magallon' and 'Castell', the commercial cultivars included as a reference were arranged in the upper half of the dendrogram (Fig. 1A) based on UPGMA analysis. Several small clusters, strongly supported by bootstrap values $>70 \%$, were arranged around the reference cultivars Roma, Blanquilla, Magallon, Williams, Bonne Louise, and Flor de Invierno. The accessions within those clusters were also closely similar to the reference cultivars in their morphological traits (Urbina et al., 2007). Other clusters with strong bootstrap support and morphological similarities included the ancient cultivars Temprana de Julio, Lombardia, Tendral, De agua, Azúcar verde, and Sermeñeta.

Analysis of Genetic STRUCTURE. Multivariate analysis (FCA) computed on all the accessions and reference cultivars displayed three partially overlapping groups (Fig. 2). Accessions of 'Roma' and 'Blanquilla' types clustered together and isolated from the others (Cluster A in Fig. 1). There was a main cluster (B) composed mostly of the same accessions that appeared in the lower half of UPGMA dendrogram, along with 'Magallon' and 'Castell'. The third cluster $(\mathrm{C})$ grouped the remaining reference cultivars with accessions mostly placed in the upper third of the dendrogram. With the 126 unique accessions and 13 reference cultivars used in this study, the most probable value of $k$ for Bayesian analysis was $k=3$. Among the subsequent 10 separate MCMC chains run with $k=3$, individual assignments to groups were highly correlated $(>0.95)$ among runs. The affinity of most individuals $(80 \%)$ to their assigned groups was strong, as their respective $Q$ membership probabilities were $>0.8$ (Breton et al., 2008). In the remaining 29 accessions with lower affinities $(0.42 \leq Q<$ $0.80)$, their placement in a group reflects consistent assignments among runs. The three groups are represented with different colors in Fig. 1B. Group 1 (black) contains 34 accessions and nine reference cultivars, with the majority belonging to cluster $\mathrm{C}$ observed in FCA analysis. Group 2 (white) is composed of 18 individuals, including all 'Roma' and 'Blanquilla'-like accessions, and several

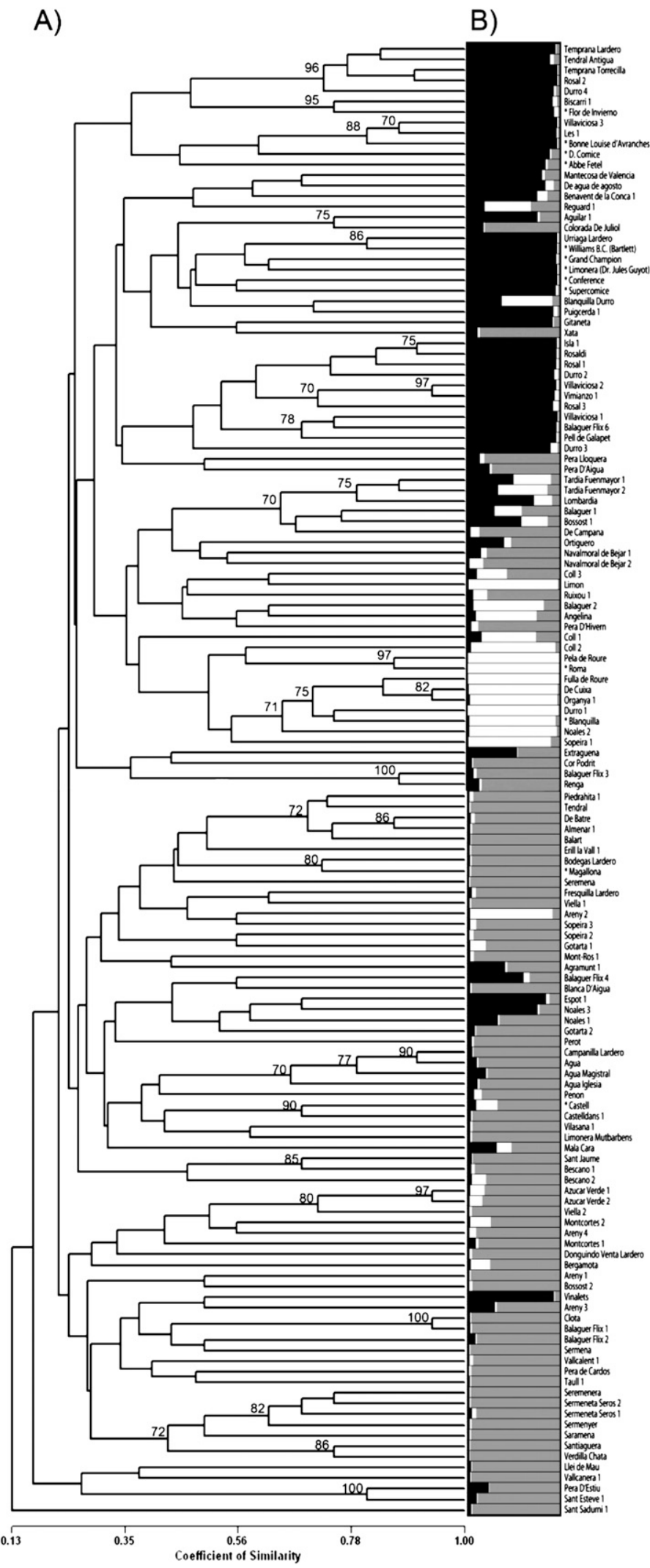

Fig. 1. Genetic relationships among the 126 unique pear accessions of the Escuela Técnica Superior de Ingeniería Agraria - Universidad de Lleida (ETSIA-UdL) pear collection and 13 cultivars used as a reference (marked with an asterisk preceding their name). (A) Dendrogram based on Nei and Li similarity matrix and UPGMA clustering. Bootstrap values $>70 \%$ are placed on branches. (B) Group probabilities obtained for $k=3$ by Bayesian clustering. Each bar represents the genetic background of an individual according to the proportion derived from each of the three different groups. Color codes for each genetic group are: group $1=$ black, group $2=$ white, group $3=$ gray. 


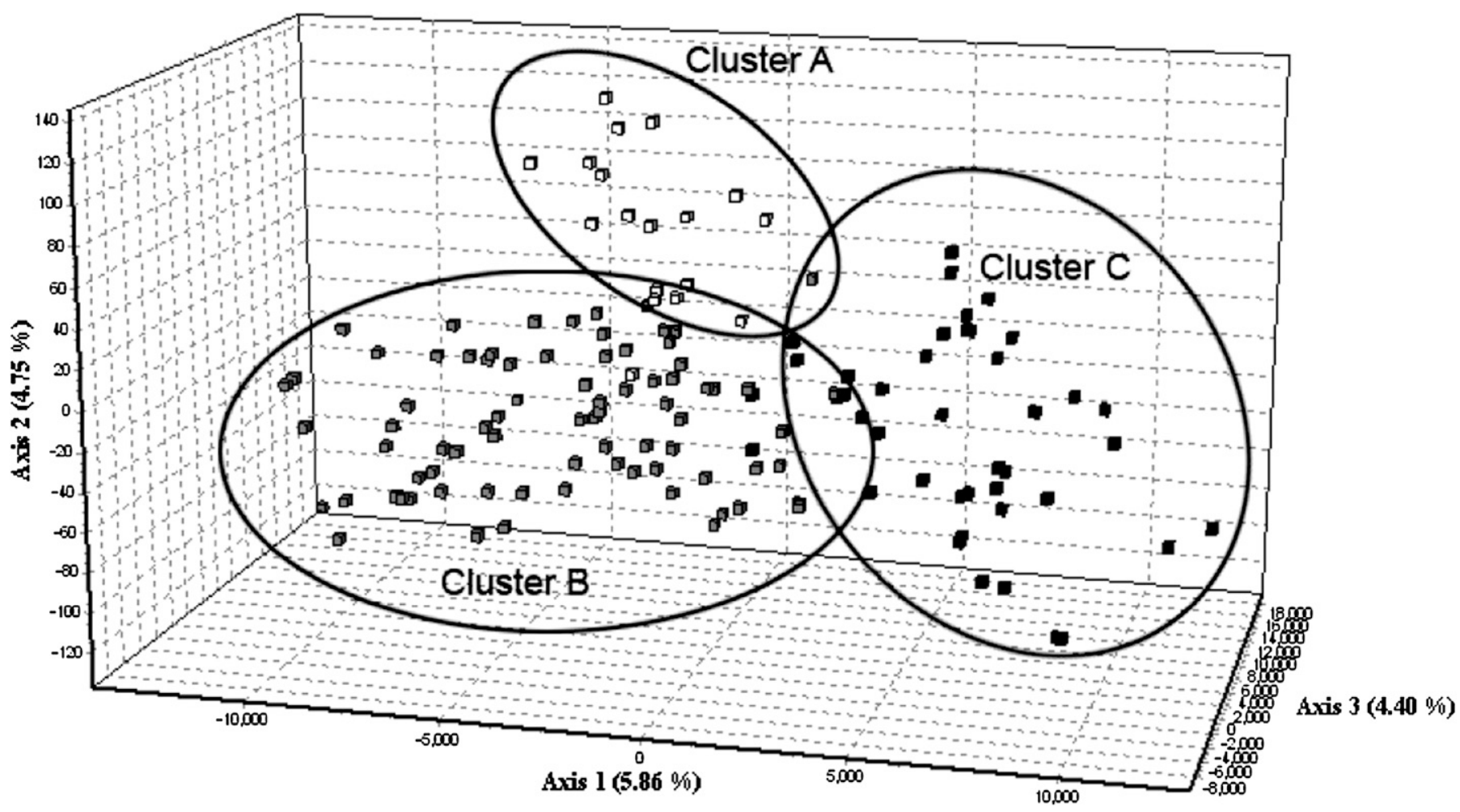

Fig. 2. Factorial correspondence analysis (FCA) based on polymorphism at eight SSR loci for 139 individuals [126 accessions from the Escuela Técnica Superior de Ingeniería Agraria - Universidad de Lleida (ETSIA-UdL) pear collection and 13 reference cultivars]. Accession colors reflect the consistent assignment using Bayesian analysis to one of the groups defined in Fig. 1B.

accessions in admixture mostly with group 1 . The third group (gray) comprises the remaining 76 accessions along with 'Magallon' and 'Castell' reference cultivars. Though there was not a straightforward correspondence between the geographic origin of the accessions and their group placement, which agrees to the traditional exchanges of plant material through grafting in the Ebro Valley provinces (La Rioja, Huesca, Teruel, and Lleida), certain grouping trends could be observed for some origins. Thus, most of the accessions with Atlantic origin (those collected in La Coruña, Pontevedra, Asturias, and Cantabria) were clustered in group 1, and most of the Mediterranean accessions collected in coastal provinces (Barcelona and Girona) were assigned to group 3.

Based on AMOVA analysis, significant variance differences were found among the three groups identified with Bayesian clustering. The overall $\mathrm{F}_{\mathrm{ST}}$ value of 0.074 suggested a moderate but highly significant $(P<0.0001)$ differentiation between groups. The highest proportion of allele variability was due to differences among accessions $(92.6 \%$ of total variation in AMOVA analysis). Genetic diversity indexes were calculated by group (Table 5). Nei's gene diversity varied from 0.74 to 0.83 , revealing a high proportion of heterozygous individuals in the three groups. However, important differences in allelic composition and richness were observed among groups. The number of alleles represented in groups 1 and 2 for each of the eight SSR was around $40 \%$ to $70 \%$ of the total, whereas group 3 represented all the alleles except for two. Regarding the alleles present in only one group (private alleles), 23 of the 24 identified were found in group 3. Moreover, the seven accessions with unique alleles (Table 3) were included within this group. Because the higher allelic diversity observed in group 3 could be due to its larger size, we calculated their allelic richness (El Mousadik and Petit, 1996) to properly evaluate allelic diversity among groups, as this rarefaction method performs scaling to the smallest group ( $\mathrm{N}=18$ in this study) to compensate for differences in size. The higher diversity observed in group 3 was

Table 5. Descriptive information for each of the three groups of genotypes identified by Bayesian clustering analyses. Summary statistics are given for each group as a whole. Summary statistics include the number of individuals in each group (N), Nei's genetic diversity, the number of alleles exclusive to the identified clusters, the number of unique alleles identified in the group, and the total number of alleles scored across all microsatellite loci. Allelic richness is scaled to the smallest group.

\begin{tabular}{|c|c|c|c|c|c|c|c|c|c|c|c|c|c|c|}
\hline \multirow{2}{*}{$\begin{array}{l}\text { Group } \\
\text { no. }\end{array}$} & \multirow{2}{*}{$\mathrm{N}$} & \multirow{2}{*}{$\begin{array}{c}\text { Gene diversity } \\
\text { (Nei) }\end{array}$} & \multicolumn{3}{|c|}{ Alleles in the group (no.) } & \multicolumn{8}{|c|}{ Alleles at each SSR locus (no.) } & \multirow{2}{*}{$\begin{array}{l}\text { Allelic } \\
\text { richness }\end{array}$} \\
\hline & & & Total & Exclusive $^{\mathrm{z}}$ & Unique $^{\mathrm{y}}$ & CH01h10 & NB103a & NB105a & NB106a & NB109a & $\mathrm{NH} 023 \mathrm{a}$ & NH029a & $\overline{R L G 1-1}$ & \\
\hline 1 & 43 & 0.75 & 60 & 0 & 0 & 8 & 7 & 9 & 5 & 11 & 5 & 8 & 7 & 6.64 \\
\hline 2 & 18 & 0.74 & 50 & 1 & 0 & 6 & 6 & 6 & 8 & 7 & 3 & 6 & 8 & 6.25 \\
\hline
\end{tabular}

${ }^{\mathrm{z}}$ Identified in only one group by Bayesian analysis.

y'dentified in only one accession. 


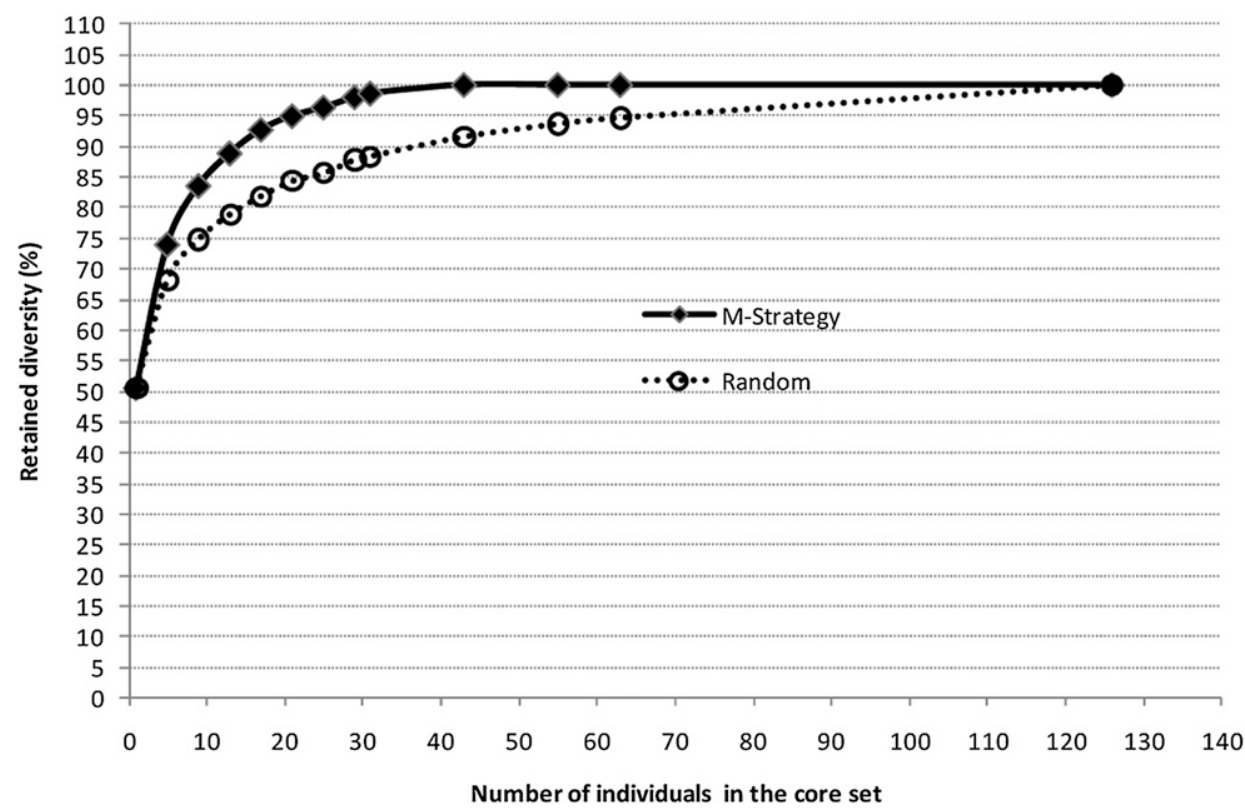

Fig. 3. Relationship between the number of individuals in the core set and the allelic diversity (\%) retained. of that which is existent within the species and that the germplasm curated at the ETSIA-UdL collection is a good instance of genetic distinctness with respect to the main pear cultivars used in European orchards. Therefore, the genetic variability found among ancient Spanish pear cultivars needs to be further studied and preserved as a potential source of desirable traits for the modern pear growing to optimize breeding progress.

\section{Literature Cited}

Bao, L., K. Chen, D. Zhang, Y. Cao, T. Yamamoto, and Y. Teng. 2007. Genetic diversity and similarity of pear (Pyrus L.) cultivars native to East Asia revealed by SSR (simple sequence repeat) markers. Genet. Resources Crop Evol. 54:959-971.

Bassam, B.J., G. Caetano-Anollés, and P.M. Gresshoff. 1991. Fast and sensi-

confirmed, as it showed (Table 3) much higher allelic richness than the others.

The results obtained through the different approaches used to analyze the genetic structure of the collection were coherent, revealing three groups with moderate, but significant, differentiation. The identification of private alleles, the clustering of all accessions with unique alleles in only one group, and remarkable differences in allelic richness among groups constitute further evidence of the uniqueness of this material. It is remarkable that most of the cultivars included as a reference clustered together in group 1 in spite of being heterogeneous material from different origins. In fact, the four reference cultivars clustered in groups 2 and 3 (Blanquilla, Roma, Castell, and Magallon) are ancient southern European cultivars grown in Spain since at least the 18th and 19th centuries. Those four cultivars had already been described as very different from a diverse group of more than 50 cultivars, with European and American origins that include old cultivars and others derived from them in recent breeding programs (Wünsch and Hormaza, 2007).

Core COLLECTION. The relationship between sample size and allelic diversity (Fig. 3) showed that $>99 \%$ of the diversity could be retained with a 35-member core set. The consensus set of accessions identified for the ETSIA-UdL pear core collection are indicated in bold in Table 1. The total number of alleles recovered in the core, and $\mathrm{H}_{\mathrm{e}}$ and $\mathrm{H}_{\mathrm{o}}$, were similar $(P>0.05)$ to those of the whole collection $\left(\mathrm{H}_{\mathrm{o}-\mathrm{UdL}}=0.734 \pm 0.151, \mathrm{H}_{\text {o-core }}=0.735 \pm 0.076\right.$; $\left.\mathrm{H}_{\mathrm{e}-\mathrm{UdL}}=0.828 \pm 0.076, \mathrm{H}_{\mathrm{e} \text {-core }}=0.850 \pm 0.054\right)$. Regarding the allele frequencies, the chi-squared tests showed that the core subset had a similar $(P>0.05)$ allelic distribution for all eight loci. As a whole, the accessions selected for the core set constitute a representative sample of the diversity retained in the ETSIAUdL collection. The maximization strategy has narrowed the collection to a smaller representative sample with a minimum of redundancy, constituting an efficient and accessible entry point in the ETSIA-UdL pear collection for breeding and research communities.

Our results highlight that the overall genetic diversity represented in currently cultivated pears is only a small fraction tive silver staining of DNA in polyacrylamide gels. Anal. Biochem. 196:80-83. Molecular fingerprints identify historic pear trees in two U.S. National Parks. Acta Hort. 800:417-422.

Bassil, N., K.E. Hummer, J.D. Postman, G. Fazio, A. Baldo, I. Armas, and R. Williams. 2009. Nomenclature and genetic relationships of apples and pears from Terceira Island. Genet. Resources Crop Evol. 56:339-352.

Belkhir, K., P. Borsa, L. Chikhi, N. Raufaste, and F. Bonhomme. 1996-2004. GENETIX 4.05, logiciel sous Windows TM pour la génétique des populations. Laboratoire Génome, Populations, Interactions, Université de Montpellier II, Montpellier, France.

Bell, R.L. 1991. Pears (Pyrus), p. 657-697. In: J.N. Moore and J.R. Ballington, Jr. (eds.). Genetic resources of temperate fruit and nut crops. Intl. Soc. Hort. Sci., Wageningen, The Netherlands.

Berg, E.E. and J.L. Hamrick. 1997. Quantification of genetic diversity at allozyme loci. Can. J. For. Res. 27:415-424.

Breton, C., C. Pinatel, F. Médail, F. Bonhomme, and A. Bervillé. 2008. Comparison between classical and Bayesian methods to investigate the history of olive cultivars using SSR-polymorphisms. Plant Sci. 175:524-532.

Brini, W., M. Mars, and J.I. Hormaza. 2008. Genetic diversity in local Tunisian pears (Pyrus communis L.) studied with SSR markers. Sci. Hort. 115:337-341.

Brown, A.H.D. 1989. Core collections: A practical approach to genetic resources management. Genome 31:818-824.

El Mousadik, A. and R.H. Petit. 1996. High level of genetic differentiation for allelic richness among populations of the argan tree [Argania spinosa (L.) Skeels] endemic of Morocco. Theor. Appl. Genet. 92:832-839.

Evanno, G., S. Gegnaut, and J. Goudet. 2005. Detecting the number of clusters of individuals using the software Structure: A simulation study. Mol. Ecol. 14:2611-2620.

Excoffier, L., G. Laval, and S. Schneider. 2005. Arlequin ver. 3.0: An integrated software package for population genetics data analysis. Evol. Bioinform. Online 1:47-50.

Felsenstein, J. 1989. PHYLIP: Phylogeny inference package (version 3.2). Cladistics 5:164-166.

Fernández-Fernández, F., N.G. Harvey, and C.M. James. 2006. Isolation and characterization of polymorphic microsatellite markers
Bassil, N., J. Postman, K. Hummer, S. Dolan, and L. Lawliss. 2008. 
from european pear (Pyrus communis L.). Mol. Ecol. Notes 6:10391041.

Food and Agriculture Organization of the United Nations. 2010. FAO statistics database on the World Wide Web. 31 Jan. 2010. $<$ http:// faostat.fao.org/site/567/DesktopDefault.aspx?PageID=567\#ancor $>$.

Food and Agriculture Organization of the United Nations/International Plant Genetic Resources Institute. 2001. Multi-crop passport descriptors. FAO/IPGRI, Rome.

Fulton, T.M., J. Chunwongse, and S.D. Tanksley. 1995. Microprep protocol for extraction of DNA from tomato and other herbaceous plants. Plant Mol. Biol. Rpt. 13:207-209.

Ghosh, A.K., L.N. Lukens, D.M. Hunter, and J.N. Strommer. 2006. European and asian pears: Simple sequence repeat-polyacrylamide gel electrophoresis-based analysis of commercially important North American cultivars. HortScience 41:304-309.

Gianfranceschi, L., N. Seglias, R. Tarchini, M. Komjanc, and C. Gessler. 1998. Simple sequence repeats for the genetic analysis of apple. Theor. Appl. Genet. 96:1069-1076.

Goudet, J. 1995. FSTAT, a program for IBM PC compatibles to calculate Weir and Cockerham's (1984) estimators of F-statistics. J. Hered. 86:485-486.

Gouesnard, B., T.M. Bataillon, G. Decoux, C. Rozale, D.J. Schoen, and J.L. David. 2001. MSTRAT: An algorithm for building germplasm core collections by maximizing allelic or phenotypic richness. J. Hered. 92:93-94.

Grenier, C., M. Deu, S. Kresovich, P.J. Bramel-Cox, and P. Hamon. 2000. Assessment of genetic diversity in three subsets constituted from the ICRISAT sorghum collection using random vs. non-random sampling procedures. B. Using molecular markers. Theor. Appl. Genet. 101:197-202.

Hemmat, M., N.F. Weeden, and S.K. Brown. 2003. Mapping and evaluation of Malus $\times$ domestica microsatellites in apple and pear. J. Amer. Soc. Hort. Sci. 128:515-520.

Jiang, Z., F. Tang, H. Hunag, H. Hu, and Q. Chen. 2009. Assessment of genetic diversity of Chinese sand pear landraces (Pyrus pyrifolia Nakai) using simple sequence repeat markers. HortScience 44:619-626.

Katayama, H., S. Adachi, T. Yamamoto, and C. Uematsu. 2007. A wide range of genetic diversity in pear (Pyrus ussuriensis var. aromatic) genetic resources from Iwate, Japan revealed by SSR and chloroplast DNA markers. Genet. Resources Crop Evol. 54:1573-1585.

Kimura, T., Y.Z. Shi, M. Shoda, K. Kotobuki, N. Matsuta, T.H.Y. Ban, and T. Yamamoto. 2002. Identification of asian pear varieties by SSR analysis. Breed. Sci. 52:115-121.

Nei, M. 1987. Molecular evolutionary genetics. Columbia Univ. Press, New York.

Nei, M. and W.H. Li. 1979. Mathematical model for studying genetic variation in terms of restriction endonucleases. Proc. Natl. Acad. Sci. USA 76:5269-5273.
Pritchard, J.K., M. Stephans, and P. Donnelly. 2000. Inference of population structure using multilocus genotype data. Genetics 155 : 945-959.

Rosenberg, N.A. 2004. Distruct: A program for the graphical display of population structure. Mol. Ecol. Notes 4:137-138.

Santesteban, L.G., C. Miranda, and J.B. Royo. 2009. Assessment of the genetic and phenotypic diversity maintained in apple core collections constructed by using either agro-morphologic or molecular marker data. Span. J. Agr. Res. 7:572-584.

Schlötterer, C. 2004. The evolution of molecular markers: Just a matter of fashion? Nat. Rev. Genet. 5:63-69.

Schoen, D.J. and A.H.D. Brown. 1995. Maximizing genetic diversity in core collections of wild relatives of crop species, p. 55-76. In: T. Hodgkin, A.H.D. Brown, T.J.L. van Hintum, and A.E.V. Morales (eds.). Core collections of plant genetic resources. Wiley, New York.

Sisko, M., B. Javornik, A. Siftar, and A. Ivancic. 2009. Genetic relationships among Slovenian pears assessed by molecular markers. J. Amer. Soc. Hort. Sci. 134:97-108.

Tessier, R., J. David, P. This, J.M. Boursiquot, and A. Charrier. 1999. Optimization of the choice of molecular markers for varietal identification in Vitis vinifera L. Theor. Appl. Genet. 98:171-177.

Urbina, V., J. Dalmases, and M. Pascual. 2007. Situación actual del banco de germoplasma de peral y manzano de la Universidad de Lleida. Acta Hort. 48:386-392.

Volk, G.M., C.M. Richards, A.D. Henk, A.A. Reilley, N.V. Bassil, and J.D. Postman. 2006. Diversity of wild Pyrus communis based on microsatellite analyses. J. Amer. Soc. Hort. Sci. 131:408-417.

World Apple and Pear Association. 2009. European apple and pear crop forecast report. World Apple and Pear Assn., Brussels, Belgium. Wünsch, A. and J.I. Hormaza. 2007. Characterization of variability and genetic similarity of european pear using microsatellite loci developed in apple. Sci. Hort. 113:37-43.

Xuan, H. 2008. Identifying european pear (Pyrus communis L.) cultivars at the KOB by using apple SSRs. Acta Hort. 800:439-445.

Yamamoto, T., T. Kimura, M. Shoda, T. Imai, T. Saito, Y. Sawamura, K. Kotobuki, T. Hayashi, and N. Matsuta. 2002c. Genetic linkage maps constructed by using an interspecific cross between japanese and european pears. Theor. Appl. Genet. 106:9-18.

Yamamoto, T., T. Kimura, M. Shoda, Y. Ban, T. Hayashi, and N. Matsuta. 2002a. Development of microsatellite markers in the japanese pear (Pyrus pyrifolia Nakai). Mol. Ecol. Notes 2:14-16.

Yamamoto, T., T. Kimura, Y. Sawamura, K. Kotobuki, Y. Ban, T. Hayashi, and N. Matsuta. 2001. SSR isolated from apple can identify polymorphism and genetic diversity in pear. Theor. Appl. Genet. 102:865-870.

Yamamoto, T., T. Kimura, Y. Sawamura, T. Manabe, K. Kotobuki, T. Hayashi, Y. Ban, and N. Matsuta. 2002b. Simple sequence repeats for genetic analysis in pear. Euphytica 124:129-137. 